\title{
Predição da Composição Química Corporal de Bovinos Nelore e F1 Simental x Nelore a partir da Composição Química da Seção Hankins e Howe (Seção HH) ${ }^{1}$
}

\author{
Antonia Sherlânea Chaves Véras ${ }^{2}$, Sebastião de Campos Valadares Filho ${ }^{3}$, José Fernando \\ Coelho da Silva ${ }^{4}$, Mário Fonseca Paulino ${ }^{3}$, Paulo Roberto Cecon ${ }^{5}$, Rilene Ferreira Diniz \\ Valadares $^{6}$, Marcelo de Andrade Ferreira ${ }^{2}$, Claudeci Martins da Silva ${ }^{7}$, Bruno Ceolin da Silva ${ }^{8}$
}

RESUMO - Utilizaram-se 30 bovinos Nelore, não-castrados, com peso médio de $330 \mathrm{~kg}$ e idade média de 20 meses, para se obterem equações de predição da composição química corporal, a partir da composição química da seção HH (Hankins e Howe). Após um período de adaptação de 40 dias, cinco animais foram abatidos para servir como referência para a estimativa do peso do corpo vazio e da composição corporal iniciais dos 25 remanescentes, os quais foram distribuídos em cinco tratamentos com diferentes níveis de concentrado na matéria seca das dietas $(25,0 ; 37,5 ; 50,0 ; 62,5 ;$ e $75,0 \%)$, em delineamento inteiramente casualizado, com cinco repetições. O peso de abate foi determinado em $450 \mathrm{~kg}$. Foram ajustadas equações de regressão linear para a predição da composição química corporal, a partir da composição química da seção HH dos animais Nelore (30 observações), e também foram acrescentados dados relativos a 29 bovinos F1 Simental x Nelore, não-castrados. Concluiu-se que a composição química corporal pode ser predita a partir da composição química da seção HH. Contudo, ressalta-se que as equações de predição da composição física da carcaça a partir da seção HH foram utilizadas para a composição do corpo vazio de ambos animais Nelore e F1 Simental x Nelore.

Palavras-chave: composição química corporal, F1 Simental x Nelore, Nelore, seção HH

\section{Prediction of the Body Chemical Composition of Nellore and F1 Simental $x$ Nellore from the Chemical Composition of the Hankins e Howe Section (Section HH)}

\begin{abstract}
Thirty Nellore bulls, averaging $330 \mathrm{~kg}$ and 20 months of age, were used to obtain the prediction equations of body chemical composition, from the chemical composition of section HH (Hankins and Howe). After a period of adaptation of 40 days, five animals were slaughtered as reference to estimate the empty body weight and the initial body composition of the 25 animals remaining, that were allotted to five treatments with different dietary levels of concentrate in the dry matter $(25.0,37.5,50.0,62.5$, and $75.0 \%)$, in a completely randomized design, with five replicates. The slaughter weight was established in $450 \mathrm{~kg}$. Linear regression equations were fitted to the prediction of body chemical composition, from the chemical composition of section HH of Nellore (30 observations), as well as data of $29 \mathrm{~F} 1$ Simental $x$ Nellore bulls. It was concluded that the body chemical composition can be predicted from the chemical composition of the section HH. However, it should be inferred that the prediction equation of carcass physical composition from the section HH were used for the empty body composition of both Nellore and F1 Simental x Nellore bulls.
\end{abstract}

Key Words: chemical composition, F1 Simental x Nellore, Nellore, section HH

\section{Introdução}

Em estudos de nutrição animal, a determinação da composição corporal de bovinos de corte é importante para a avaliação do desempenho, visando a produção de carcaças com maior proporção de músculos e quantidades adequadas de gordura, para atender as exigências do mercado consumidor, bem como para a estimativa de suas exigências nutricionais.
A medida mais utilizada para avaliar o crescimento animal é o ganho de peso corporal. Contudo, durante o crescimento, ocorrem variações no peso e tamanho dos animais, bem como mudanças nas proporções dos tecidos depositados.

Os componentes químicos do corpo (água, proteína, gordura e elementos minerais) variam, durante o crescimento, de forma paralela à composição física (tecidos muscular, ósseo e adiposo), e ambos são

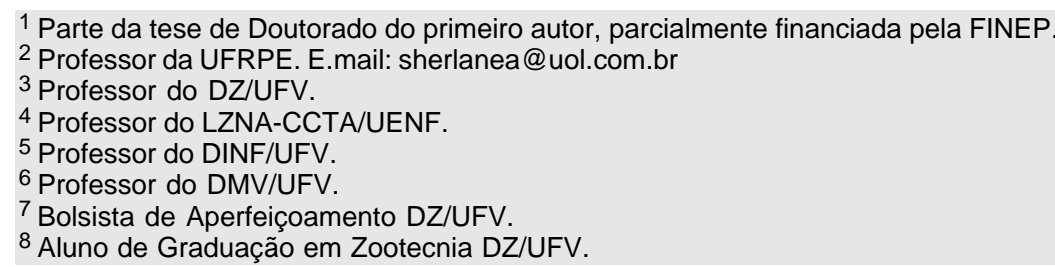


influenciados por diversos fatores como idade, peso, raça, condição sexual e nível nutricional dos animais, com reflexos nos custos de produção e na qualidade da carne. Portanto, é fundamental que métodos rápidos e econômicos para estimativa da composição física e química da carcaça e/ou do corpo animal sejam disponíveis.

Os métodos utilizados para predição da composição corporal e/ou da carcaça são classificados em diretos ou indiretos. Os métodos indiretos envolvem a predição da composição, tanto do corpo, quanto da carcaça dos animais, a partir de parâmetros mais facilmente obtidos. Já os métodos diretos consistem na separação e dissecação de todas as partes do corpo dos animais, e subsequente determinação dos constituintes físicos e químicos, sendo portanto, mais acurados. Contudo, além de laboriosos, estes últimos não permitem a comercialização das carcaças. Assim, vários métodos indiretos têm sido desenvolvidos para predição da composição do corpo ou da carcaça dos animais.

Os métodos indiretos são divididos naqueles que permitem estimar a composição do corpo ou da carcaça nos animais vivos e a estimativa a partir da carcaça, ou de partes da carcaça.

As estimativas com animais vivos, podem ser subjetivas, como avaliação da conformação, ou objetivas, como medidas da superfície, do volume e do comprimento corporais; ultra-sonografia; impulsos elétricos obtidos a partir da passagem de animais por uma câmara equipada com corrente elétrica; mensuração da radioatividade do 40K (HEDRICK, 1983); técnicas de diluição com indicadores para estimar a água corporal, que é relacionada com o conteúdo de gordura (ALHASSAN et al., 1975; KOCK e PRESTON, 1979; e HEDRICK, 1983). Os métodos subjetivos dependem da experiência do avaliador e não são recomendados em trabalhos científicos (HEDRICK, 1983).

Os métodos indiretos efetuados na carcaça, ou em partes dela, ou do corpo dos animais, incluem o uso da gravidade específica (ALHASSAN et al., 1975; HEDRICK, 1983); composição de cortes (ALHASSAN et al., 1975); composição da seção entre a $9^{\mathrm{a}}$ e $11^{\mathrm{a}}$ costelas (HANKINS e HOWE, 1946); ultra-sonografia, provas de reflectância ótica e outros métodos eletrônicos efetuados na carcaça quente (BERG et al., 1997). Face a várias limitações, tanto operacionais, quanto de custos, da utilização de tecnologias mais modernas para estimativa da composição da carcaça e do corpo dos animais, os métodos mais utilizados são a gravidade específica e a seção entre a $9^{\mathrm{a}}$ e a $11^{\mathrm{a}}$ costelas (seção HH) da carcaça.

HANKINS e HOWE (1946) conduziram experimento sobre a utilização de cortes da carcaça para predição, tanto da composição física, quanto da composição química da carcaça de bovinos. Este trabalho apresenta uma metodologia para obtenção de uma amostra da carcaça compreendendo a seção entre a $9^{a}$ e $11^{a}$ costelas (seção $\mathrm{HH}$ ), bem como estabelece equações de predição das referidas composições. Em relação à composição química, os referidos autores observaram correlações significativas de 0,$91 ; 0,83$; e 0,53 entre os teores de gordura, proteína e cinzas da seção $\mathrm{HH}$ e aqueles obtidos por meio de análise química das carcaças de 84 novilhos.

O baixo valor preditivo da gravidade específica para composição corporal tem sido observado em animais cujo conteúdo de gordura no corpo é inferior a 12\% (PRESTON et al., 1974), ou a 20\% (GIL et al.,1970; ALHASSAN et al., 1975; ROHR e DAENICLE, 1984). JONES et al. (1978) atentaram para o fato de que, na maioria dos ensaios conduzidos, não se faz referência à retirada, ou não, da gordura renal e/ou pélvica, podendo ser este o motivo das variações nos resultados com o uso do método da gravidade específica.

No Brasil, SALVADOR (1980) não encontrou diferença significativa entre a composição da carcaça estimada por análise química e por gravidade específica da seção $\mathrm{HH}$, ou por gravidade específica da carcaça, com animais azebuados. Semelhantemente, TEIXEIRA (1984) não observou diferença estatística entre a composição corporal estimada por meio da gravidade específica da carcaça, ou da seção $\mathrm{HH}$, em bovídeos de seis grupos genéticos. GONÇALVES (1988) comparou os métodos de gravidade específica da carcaça ou da seção $\mathrm{HH}$, análise química dos tecidos e espaço de água tritiada, e concluiu que a gravidade específica da seção HH e o espaço de água tritiada poderiam ser utilizados para estimativa da composição química corporal de zebuínos, taurinos e bubalinos. PERON et al. (1993), estimando a composição corporal de novilhos de diferentes grupos genéticos com o uso de métodos indiretos, concluíram que a gravidade específica da seção HH pode ser utilizada em estudos comparativos da composição corporal.

As equações propostas por HANKINS e HOWE (1946) são amplamente utilizadas no exte- 
1114 Rev. bras. zootec.

rior, devido à facilidade de obtenção da seção HH e, recentemente, NOUR e THONNEY (1994) validaram as equações para predição da composição química da carcaça de bovinos Angus e Holandês a partir da composição da seção $\mathrm{HH}$, sugerindo pequenos ajustes para o tipo racial.

ALHASSAN et al. (1975), a partir das porcentagens de gordura, proteína e cinzas na seção $\mathrm{HH}$, obtiveram coeficientes de determinação de $0,94 \mathrm{e}$ 0,96 , respectivamente, para predição da porcentagem de gordura no corpo vazio de animais pertencentes às raças Hereford e Angus. Contudo, não encontraram equações capazes de estimar, com precisão, as porcentagens de proteína e cinzas no corpo dos animais.

JORGE et al. (1998), trabalhando com zebuínos não-castrados confinados, observaram elevados coeficientes de determinação para as estimativas das porcentagens de proteína, gordura, cálcio $(\mathrm{Ca})$, fósforo $(\mathrm{P})$, potássio $(\mathrm{K})$ e sódio $(\mathrm{Na})$ e do conteúdo energético do corpo vazio, em função dos obtidos para a seção $\mathrm{HH}$, o mesmo não acontecendo para o magnésio $(\mathrm{Mg})$. Também, elevados coeficientes de correlação foram observados por FERREIRA e VALADARES FILHO (1999), com animais F1 Simental x Nelore, não-castrados, em confinamento.

OLIVEIRA (1999) obteve elevados coeficientes de determinação para as equações de predição das porcentagens de proteína, gordura, cinzas e água, e do conteúdo de energia do corpo vazio, em função da composição da seção $\mathrm{HH}$, em mestiços Gir-Holando, castrados, mantidos em pastagem de capim-elefante, durante a estação chuvosa.

Face ao exposto, o objetivo deste trabalho foi obter equações de predição da composição química corporal, a partir da composição química da seção HH (Hankins e Howe) de bovinos.

\section{Material e Métodos}

O local de condução do experimento, as instalações, as dietas (proporção dos ingredientes e composição), o sistema de alimentação e o manejo dos animais foram descritos com detalhes por VÉRAS et al. (2000).

Foram utilizados 30 bovinos Nelore, não-castrados, com peso médio de $330 \mathrm{~kg}$ e idade média de 20 meses. Após um período de adaptação de 40 dias, cinco animais (animais referência) foram abatidos para servir como referência para a estimativa do peso do corpo vazio (PCVZ) e da composição corporal iniciais dos 25 remanescentes. Estes foram distribuídos em cinco tratamentos com diferentes níveis de concentrado na matéria seca das dietas $(25,0 ; 37,5 ; 50,0 ; 62,5 ;$ e $75,0 \%)$, em delineamento inteiramente casualizado, com cinco repetições.

$O$ peso de abate foi preestabelecido em $450 \mathrm{~kg}$ de peso vivo (PV). Antes do abate, os animais foram submetidos a jejum de 16 horas. Após o abate, $\mathrm{o}$ aparelho gastrintestinal de cada animal foi esvaziado e, juntamente com os órgãos, foram lavados, cujos pesos foram somados aos das demais partes do corpo (carcaça, cabeça, couro, cauda, pés e sangue), para determinação do PCVZ. A relação obtida entre o PCVZ e o PV dos animais referência foi utilizada para a estimativa do PCVZ inicial dos animais que permaneceram no experimento. Dentro de cada tratamento, aleatoriamente foi sorteado um animal para representá-lo, do qual foram retiradas amostras da cabeça e de um membro anterior e outro posterior, para separação física de músculos, gordura, ossos e couro e análises laboratoriais.

A carcaça de cada animal foi dividida em duas meia-carcaças, as quais foram pesadas e, em seguida, resfriadas em câmara fria a $-5^{\circ} \mathrm{C}$, durante 18 horas. Em seguida, as meia-carcaças foram retiradas da câmara fria, quando foi coletada e pesada uma amostra da meia-carcaça esquerda, correspondente à seção entre a $9^{\mathrm{a}}$ e $11^{\mathrm{a}}$ costelas (seção $\mathrm{HH}$ ), para posteriores dissecação e predição das proporções de músculos, ossos e tecido adiposo na carcaça, segundo equações preconizadas por HANKINS e HOWE (1946):

Proporção de músculo: $\mathrm{Y}=16,08+0,80 \mathrm{X}$;

Proporção de tecido adiposo: $\mathrm{Y}=3,54+0,80 \mathrm{X}$;

Proporção de ossos: $\mathrm{Y}+5,52+0,57 \mathrm{X}$,

em que: $X=$ porcentagem dos componentes na seção HH.

As amostras de rúmen, retículo, omaso, abomaso, intestino delgado, intestino grosso, gordura interna e mesentério foram agrupadas de forma proporcional e constituíram amostra composta de vísceras; enquanto as amostras de fígado, coração, rins, pulmão, língua, baço, carne industrial e aparas (esôfago, traquéia e aparelho reprodutor) também foram agrupadas de forma proporcional e compuseram amostra de órgãos.

As amostras de sangue foram coletadas imediatamente após o abate, acondicionadas em recipi- 
ente de vidro e levadas à estufa de ventilação forçada, a $55-60^{\circ} \mathrm{C}$, durante 48 a 72 horas, para determinação do teor de matéria seca (MS), sendo, a seguir, moídas em moinho de bola e acondicionadas em recipientes para posteriores análises de nitrogênio total, extrato etéreo $(\mathrm{EE})$, cálcio $(\mathrm{Ca})$, fósforo $(\mathrm{P})$, magnésio $(\mathrm{Mg})$ e potássio $(\mathrm{K})$, conforme SILVA (1990); sendo que a porcentagem de proteína foi obtida pelo produto entre o teor de nitrogênio total e o fator 6,25 . A solução mineral para determinação dos macroelementos minerais foi preparada por via úmida e, após as devidas diluições, o teor de $\mathrm{P}$ foi determinado por colorimetria, os de $\mathrm{Ca}$ e $\mathrm{Mg}$, em espectrofotômetro de absorção atômica, e os de K, em espectrofotômetro de chama.

À exceção das amostras de sangue, as amostras compostas de órgãos (200 g) e de vísceras (200 g), de músculos (200 g) e gordura (200 g), após moídas; e as de couro (100 g), ossos (100 g) e cauda (100 g), após seccionadas, foram acondicionadas em vidros com capacidade de $500 \mathrm{~mL}$ e levadas à estufa a $105^{\circ} \mathrm{C}$, por um período entre 48 a 72 horas, para a determinação da matéria seca gordurosa (MSG).

Posteriormente, procedeu-se ao desengorduramento das referidas amostras com lavagens sucessivas com éter de petróleo, obtendo-se a matéria seca pré-desengordurada (MSPD). Em seguida, as amostras foram moídas em moinho de bola, para posteriores determinações de nitrogênio total, EE e elementos inorgânicos, segundo SILVA (1990). A gordura removida no pré-desengorduramento foi calculada pela diferença entre a MSG e a MSPD e adicionada aos resultados obtidos para o extrato etéreo residual na MSPD, para determinação do teor total de gordura. A partir do conhecimento dos teores de proteína, EE e elementos minerais na MSPD e do peso da amostra submetida ao pré-desengorduramento, determinaram-se os respetivos teores na matéria natural.

Os conteúdos corporais de gordura, proteína e minerais foram determinados em função de suas concentrações percentuais nos órgãos, nas vísceras, no couro, no sangue, na cauda, na cabeça, nos pés (gordura e ossos) e nos constituintes separados (gordura, músculos e ossos) da seção HH, representando a composição física da carcaça.

A determinação da energia corporal foi obtida a partir dos teores corporais de proteína e gordura e seus respectivos equivalentes calóricos, confor- me a equação preconizada pelo ARC (1980):

$$
\mathrm{CE}=5,6405 \mathrm{X}+9,3929 \mathrm{Y}
$$

em que: $\mathrm{CE}=$ conteúdo energético (Mcal); $\mathrm{X}=$ proteína corporal $(\mathrm{kg}) ; \mathrm{e} \mathrm{Y}=\operatorname{gordura}$ corporal $(\mathrm{kg})$.

As equações de predição da composição corporal (proteína, gordura, energia, cinzas, $\mathrm{Ca}, \mathrm{P}, \mathrm{Mg}$ e K) foram ajustadas em função da composição da seção HH, utilizando-se o seguinte modelo:

$$
\mathrm{Y}=\mathrm{a}+\mathrm{bX}+\mathrm{e}
$$

em que: $\mathrm{Y}=$ porcentagem de proteína, gordura, cinzas, $\mathrm{Ca}, \mathrm{P}, \mathrm{Mg}$ ou $\mathrm{K}$ e energia (Mcal) no corpo vazio; $a=$ efeito da média (intercepta); $b=$ coeficiente de regressão das porcentagens de proteína, gordura, $\mathrm{Ca}, \mathrm{P}, \mathrm{Mg}$ ou K e energia (Mcal) no corpo vazio, em função das porcentagens de proteína, gordura, $\mathrm{Ca}, \mathrm{P}, \mathrm{Mg}$ ou $\mathrm{K}$ e energia (Mcal) na seção $\mathrm{HH}$; $\mathrm{X}=$ porcentagem de proteína, gordura, $\mathrm{Ca}, \mathrm{P}, \mathrm{Mg}$ ou $\mathrm{K}$ e energia (Mcal) na seção $\mathrm{HH}$; e e = erro aleatório.

Também foram ajustadas equações de regressão no mesmo modelo apresentado anteriormente, incluindo aos dados do presente trabalho (30 observações), os obtidos para as porcentagens de proteína, gordura, $\mathrm{Ca}, \mathrm{P}, \mathrm{Mg}$ e K e o conteúdo energético, tanto no corpo vazio, quanto na seção $\mathrm{HH}$, por FERREIRA e VALADARES FILHO (1999) com bovinos F1 Simental x Nelore (29 observações).

\section{Resultados e Discussão}

Os parâmetros das equações de regressão das porcentagens de gordura e proteína e do conteúdo energético no corpo vazio, em função destes mesmos parâmetros na seção HH dos animais Nelore, são apresentados na Tabela 1 .

Como pode ser observado, para a porcentagem de gordura e para o conteúdo energético no corpo dos animais, os coeficientes de determinação, embora inferiores aos relatados por PERON et al. (1993) e OLIVEIRA (1999), foram elevados, demonstrando bom ajustamento das equações aos dados experimentais. Contudo, a equação obtida para a composição protéica, não foi capaz de estimar, com precisão, a porcentagem de proteína no corpo vazio dos animais. Resultado semelhante foi verificado por ALHASSAN et al. (1975).

Quando foram adicionados aos dados do presente trabalho, os obtidos por FERREIRA e VALADARES FILHO (1999), para bovinos F1 Simental x Nelore, totalizando 59 observações, houve melhoria nos coeficientes de determinação das equações para as 
1116 Rev. bras. zootec.

Tabela 1 - Parâmetros das equações de regressão das porcentagens de gordura e proteína e do conteúdo energético (Mcal) no corpo vazio, em função das porcentagens de gordura e proteína e do conteúdo energético (Mcal) na seção $\mathrm{HH}$ de bovinos Nelore

Table 1 - Parameters of the regression equations of the percentages of fat and protein and of energy content (Mcal) in the empty body, on the fat and protein percentages and of energy content (Mcal) in the section $\mathrm{HH}$ of Nellore bulls

\begin{tabular}{lccc}
\hline \multirow{2}{*}{ Itens } & \multicolumn{3}{c}{$\begin{array}{c}\text { Parâmetros } \\
\text { Parameters }\end{array}$} \\
\cline { 2 - 4 } & $\begin{array}{c}\text { Intercepta (a) } \\
\text { Intercept }\end{array}$ & $\begin{array}{c}\text { Coeficiente (b) } \\
\text { Coefficient }\end{array}$ & $\mathrm{r}^{2}$ \\
\hline $\begin{array}{l}\text { Gordura } \\
\text { Fat }\end{array}$ & 3,2123 & 0,7658 & 0,83 \\
$\begin{array}{l}\text { Proteína } \\
\text { Protein }\end{array}$ & 5,7436 & 0,7411 & 0,49 \\
$\begin{array}{l}\text { Energia } \\
\text { Energy }\end{array}$ & 0,6042 & 0,7649 & 0,83 \\
\hline
\end{tabular}

porcentagens de gordura e proteína e para o conteúdo energético no corpo vazio dos animais (Tabela 2), permitindo recomendar o uso das referidas equações para predição da composição corporal de bovinos.

A Figura 1 ilustra as porcentagens de gordura, proteína e o conteúdo energético no corpo vazio de bovinos Nelore e F1 Simental x Nelore, em função destes parâmetros na seção HH.

Tabela 2 - Parâmetros das equações de regressão das porcentagens de gordura e proteína e do conteúdo energético (Mcal) no corpo vazio, em função das porcentagens de gordura e proteína e do conteúdo energético (Mcal) na seção HH de bovinos Nelore e F1 Simental x Nelore

Table 2 - Parameters of the regression equations of the percentages of fat and protein and of energy content (Mcal) in the empty body, on the fat and protein percentages and of energy content (Mcal) in the section $\mathrm{HH}$ of Nellore and F1 Simental $x$ Nellore bulls

\begin{tabular}{lccc}
\hline \multirow{2}{*}{ Itens } & \multicolumn{3}{c}{$\begin{array}{c}\text { Parâmetros } \\
\text { Parameters }\end{array}$} \\
\cline { 2 - 4 } & $\begin{array}{c}\text { Intercepta (a) } \\
\text { Intercept }\end{array}$ & $\begin{array}{c}\text { Coeficiente (b) } \\
\text { Coefficient }\end{array}$ & $\mathrm{r}^{2}$ \\
\hline $\begin{array}{l}\text { Gordura } \\
\text { Fat }\end{array}$ & 1,8544 & 0,8359 & 0,93 \\
$\begin{array}{l}\text { Proteína } \\
\text { Protein } \\
\text { Energia } \\
\text { Energy }\end{array}$ & 4,4454 & 0,7912 & 0,63 \\
\hline
\end{tabular}
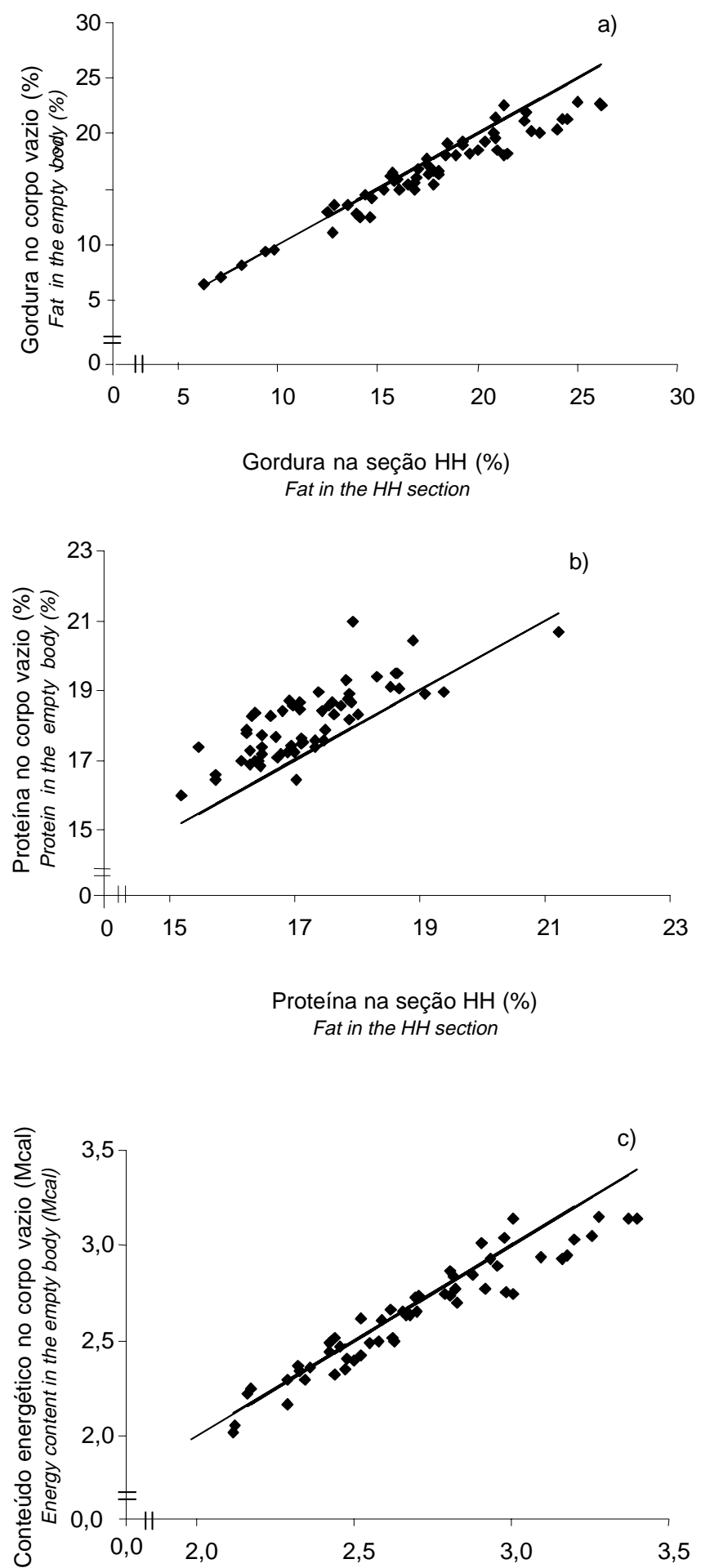

Conteúdo energético na seção $\mathrm{HH}$ (Mcal) Energy content in the $\mathrm{HH}$ section (MCal)

Figura 1 - Relação entre as porcentagens de gordura (a) e proteína (b) e o conteúdo energético, em Mcal, (c) no corpo vazio e na seção HH de bovinos Nelore e F1 Simental Nelore.

Figure 1 - Relation among the fat (a) and protein (b) percentages and the energy (c) content, in Mcal, in the empty body and in the HH section of Nellore and F1 Simental $x$ Nellore bulls. 
$\mathrm{Na}$ Tabela 3, são apresentados os parâmetros das equações de regressão das porcentagens de cinzas, Ca, P, Mg e K no corpo vazio, em função dos respectivos parâmetros na seção $\mathrm{HH}$ para os animais Nelore.

O coeficiente de determinação obtido para cinzas foi maior que os relatados por ALHASSAN et al. (1975) e por PERON et al. (1993), que trabalharam com diferentes grupos genéticos.

As equações de predição das porcentagens dos macroelementos minerais obtidas no presente trabalho mostraram-se bem ajustadas aos dados, face aos elevados coeficientes de determinação, inclusive para as porcentagens de $\mathrm{Mg}$. As equações obtidas por JORGE et al. (1998) e por FERREIRA e VALADARES FILHO (1999), ao contrário das obtidas no presente trabalho, não foram capazes de predizer, com precisão, as porcentagens de Mg no corpo vazio dos animais, a partir da porcentagem do referido mineral na seção $\mathrm{HH}$.

De forma semelhante ao que ocorreu com as porcentagens de gordura e de proteína e o conteúdo energético, quando foram incluídos os dados obtidos por FERREIRA e VALADARES FILHO (1999),

Tabela 3 - Parâmetros das equações de regressão das porcentagens de cinzas, cálcio, fósforo, magnésio e potássio no corpo vazio, em função das porcentagens de cinzas, cálcio, fósforo, magnésio e potássio na seção $\mathrm{HH}$ de bovinos Nelore

Table 3 - Parameters of the regressionequations of the percentages of ashes, calcium, phosphorus, magnesium and potassium in the empty body, on the percentages of ashes, calcium, phosphorus, magnesium and potassium in the $\mathrm{HH}$ section of Nellore bulls

\begin{tabular}{lccc}
\hline Itens & \multicolumn{3}{c}{$\begin{array}{c}\text { Parâmetros } \\
\text { Parameters }\end{array}$} \\
\cline { 2 - 4 } & $\begin{array}{c}\text { Intercepta (a) } \\
\text { Intercept }\end{array}$ & $\begin{array}{c}\text { Coeficiente (b) } \\
\text { Coefficient }\end{array}$ & $\mathrm{r}^{2}$ \\
\hline $\begin{array}{l}\text { Cinzas } \\
\text { Ashes }\end{array}$ & 0,6181 & 0,5934 & 0,89 \\
$\begin{array}{l}\text { Cálcio } \\
\text { Calcium }\end{array}$ & 0,4225 & 0,5049 & 0,90 \\
$\begin{array}{l}\text { Fósforo } \\
\text { Phosphorus } \\
\text { Magnésio } \\
\begin{array}{l}\text { Magnesium } \\
\text { Potássio }\end{array}\end{array}$ & 0,3801 & 0,4268 & 0,89 \\
Potassium & 0,0123 & 0,509 & 0,94 \\
\hline
\end{tabular}

aos dados relativos aos animais Nelore, para predição da composição do corpo vazio em macroelementos inorgânicos, os coeficientes de determinação aumentaram (Tabela 4).

Portanto, as porcentagens de $\mathrm{Ca}, \mathrm{P}, \mathrm{Mg}$ e $\mathrm{K}$ no corpo vazio mostraram-se altamente correlacionadas com as respectivas porcentagens na seção $\mathrm{HH}$, podendo-se recomendar o uso destas equações para a estimativa da composição química corporal de bovinos. A relação obtida para os dados dos animais Nelore agrupados com os F1 Simental X Nelore é apresentada na Figura 2.

Vale ressaltar que as equações de predição da composição física da carcaça a partir da seção HH, preconizadas por HANKINS e HOWE (1946), foram utilizadas para a composição do corpo vazio dos animais do presente estudo e dos utilizados por FERREIRA e VALDARES FILHO (1999). Devido ao fato de a carcaça ser o componente de maior expressão quantitativa no corpo vazio, as associações estreitas entre a composição química do corpo vazio e da carcaça, representada pela composição química da seção $\mathrm{HH}$, possivelmente são explicadas pelo uso das referidas equações.

Tabela 4 - Parâmetros das equações de regressão das porcentagens de cálcio, fósforo, magnésio e potássio no corpo vazio, em função das porcentagens de cálcio, fósforo, magnésio e potássio na seção $\mathrm{HH}$ de bovinos Nelore e F1 Simental x Nelore

Table 4 - Parameters of the regression equations of the percentages of ashes, calcium, phosphorus, magnesium and potassium in the empty body, on the percentages of ashes, calcium, phosphorus, magnesium and potassium in the HH section of Nellore and F1 Simental $x$ Nellore bulls

\begin{tabular}{lccc}
\hline \multirow{2}{*}{ Itens } & \multicolumn{3}{c}{$\begin{array}{c}\text { Parâmetros } \\
\text { Parameters }\end{array}$} \\
\cline { 2 - 4 } & $\begin{array}{c}\text { Intercepta (a) } \\
\text { Intercept }\end{array}$ & $\begin{array}{c}\text { Coeficiente (b) } \\
\text { Coefficient }\end{array}$ & $\mathrm{r}^{2}$ \\
\hline $\begin{array}{l}\text { Cálcio } \\
\text { Calcium }\end{array}$ & 0,401 & 0,5078 & 0,91 \\
$\begin{array}{l}\text { Fósforo } \\
\text { Phosphorus }\end{array}$ & 0,325 & 0,4665 & 0,91 \\
$\begin{array}{l}\text { Magnésio } \\
\text { Magnesium }\end{array}$ & 0,012 & 0,5134 & 0,99 \\
$\begin{array}{l}\text { Potássio } \\
\text { Potassium }\end{array}$ & $-0,059$ & 1,1222 & 0,90 \\
\hline
\end{tabular}


1118 Rev. bras. zootec.
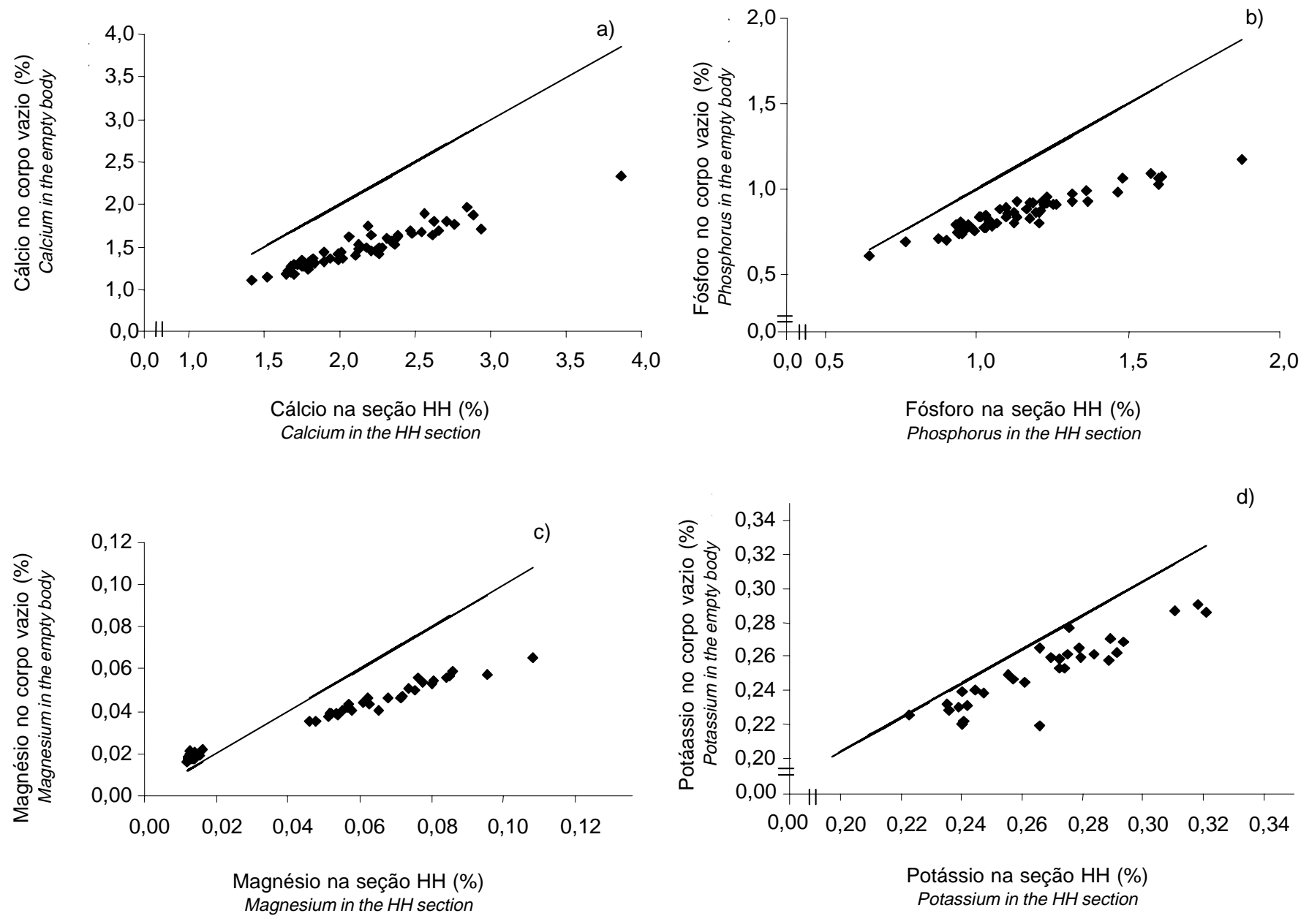

Figura 2 - Relação entre as porcentagens de Ca (a), P (b), Mg (c) e K (d) no corpo vazio e na seção HH de bovinos Nelore e F1 Simental x Nelore.

Figure 2 - Relation among the percentages of $\mathrm{Ca}(\mathrm{a}), \mathrm{P}(\mathrm{b}), \mathrm{Mg}(\mathrm{c})$ and $\mathrm{K}(\mathrm{d})$ in the empty body and in the HH section of Nellore and F1 Simental $x$ Nellore bulls.

\section{Conclusões}

A composição química corporal, em termos de gordura, proteína, energia, cálcio, fósforo, magnésio e potássio de bovinos Nelore e F1 Simental x Nelore pode ser predita a partir da composição química da seção $\mathrm{HH}$.

\section{Referências Bibliográficas}

ALHASSAN, W.S., BUCHANAN-SMITH, J.G., USBORNE, W.R. et al. 1975. Predicting empty body composition of cattle from carcass weight and rib cut composition. Can. J. Anim. Sci., 55(3):369-376.

BERG, E.P., NEARY, M.K., FORREST, J.C. et al. 1997. Evaluation of eletronic technology to assess lam carcass composition. J. Anim. Sci., 75:2433-2444.

FERREIRA, M.A., VALADARES FILHO, S.C. Composição química corporal de bovinos F1 Simental x Nelore, nãocastrados, predita através de método indireto. In: REUNIÃO ANUAL DA SOCIEDADE BRASILEIRA DE
ZOOTECNIA, 36, Porto Alegre, RS, 1999. Anais ... Porto Alegre: SBZ, 1999, p. 348.

GIL, E., JOHNSON, R.R., CAHILL, V.R. et al. 1970. An evaluation of carcass specific volume, dye dilution and empty body parameters as predictors of beef carcass fatness over a wide range of fatness. J. Anim. Sci., 31(3):459-469.

GONÇALVES, L.C. Digestibilidade, composição corporal, exigências nutricionais e características das carcaças de zebuínos, taurinos e bubalinos. Viçosa, MG: UFV, 1988. 238p. Tese (Doutorado em Zootecnia) - Universidade Federal de Viçosa, 1988.

HANKINS, O.G., HOWE, P.E. 1946. Estimation of the composition of beef carcasses and cuts. Washington, D.C. (Tech. Bulletin - USDA, 926).

HEDRICK, H.B. 1983. Methods of estimating live animal and carcass composition. J. Anim. Sci., 57(5):1316-1327.

JONES, S.D.M., PRICE, M.A., BERG, R.T. 1978. Review of carcass density, its measurement and relationship with bovine carcass fatness. J. Anim. Sci., 46(5):1151-1158.

JORGE, A.M., FONTES, C.A.A., PAULIN, M.F. et al. Predição da composição química corporal de zebuínos através de método indireto. In: REUNIÃO ANUAL DA SOCIEDADE BRASILEIRA DEZOOTECNIA, 35, 1998. Botucatu, Anais.. Botucatu, SP: SBZ, 1998. p.233-235. 
KOCK, S.W.,PRESTON, R.L. 1979.Estimation of bovine carcass composition by the urea dilution technique. J. Anim. Sci., 48(2):319-327.

NOUR, A.Y.M., THONNEY, M.L. 1994. Technical note: chemical composition of Angus and Holstein carcasses predicted from rib section composition. J. Anim. Sci., 72:1239-1241.

OLIVEIRA, R.C. Ganho de peso, características de carcaça e composição corporal de novilhos, em regime de pastejo, em capim-elefante, durante a estação chuvosa. Viçosa, MG: UFV, 1999. Dissertação (Mestrado em Zootecnia) - Universidade Federal de Viçosa, 1999.

PERON, A.J., FONTES, C.A.A., LANA, R.P. et al. 1993. Predição da composição corporal e da carcaça de bovinos através de métodos indiretos. R. Soc. Bras. Zootec., 22(2):227-237.

PRESTON, R.L., VANCE,R.D., CAHILL, V.R. et al. 1974. Carcass specific gravity and carcass composition in cattle and the effect of bone proportionality on this relationship. J. Anim. Sci., 38(1):47-51.

ROHR, K. R., DAENICKE, R. 1984. Nutritional effects on the distribuition of live weight as gastrointestinal tract fill and tissue components in growing cattle. J. Anim. Sci., 38(3):753-765.
SALVADOR, M. Exigências de energia e proteína para engorda de novilhos azebuados. Viçosa, MG: UFV, 1980. 70p. Dissertação (Mestrado em Zootecnia) - Universidade Federal de Viçosa, 1980.

TEIXEIRA, J.C. Exigências de energia e proteína, composição e área corporal e principais cortes da carcaça em seis grupos genéticos de bovídeos. Viçosa, MG: UFV, 1984. 94p. Dissertação (Mestrado em Zootecnia) - Universidade Federal de Viçosa, 1984.

VÉRAS, A.S.C., VALADARES FILHO, S.C.V., COELHO DA SILVA, J.F. et al. 2000. Consumo e digestibilidade aparente em bovinos Nelore, não-castrados, alimentados com rações contendo diferentes níveis de concentrado. Rev. bras. zootec., 29(6):2367-2378 (supl. 2).

Recebido em: 01/12/99

Aceito em: 21/02/00 